\title{
300
}

\section{EL CAMINO DEL MEDIO: BARTHES ENTRE BENJAMIN Y ADORNO}

\author{
Leandro Bohnhoff ${ }^{1}$
}

\begin{abstract}
RESUMEN: En Roland Barthes por Roland Barthes (2018 [1975]), el crítico francés nos exhorta a leer su ensayo autobiográfico como dicho por un personaje de novela. Este es uno de los hitos donde se suele ubicar el comienzo del denominado "último Barthes", etapa marcada por una voluntad expresa de que su obra tienda a la novelización. Unos años después, en la Lección inaugural (2015 [1978]) dictada en 1977, se autofigura como un "sujeto incierto" por no haber escrito más que ensayos. El presente trabajo se propone leer la escritura de La cámara lúcida (2009 [1980]) en el horizonte de esa doble tensión. El polo novelístico de dicha tensión, además de las propias inquietudes de Barthes por el carácter eminentemente realista de toda literatura, nos permite preguntarnos el modo en que el libro barthesiano sobre la fotografía pone en juego la mímesis realista a través de ciertos aportes de Walter Benjamin (Cfr. 2007). Por otro lado, el polo ensayístico, que impulsaría a formular un pensamiento verdaderamente crítico, invoca la inquietud de leer la obra en su dimensión formal (en el sentido adorniano de la expresión [Cfr. 2013]). Ambas líneas de pesquisa iluminan el problema del medio o la mediación como eje central de la tensión entre novela y ensayo.
\end{abstract}

PALABRAS CLAVE: forma, ensayo, novela, Barthes, Benjamin, Adorno.

\section{THE MIDDLE WAY: BARTHES BETWEEN BENJAMIN AND ADORNO}

ABSTRACT: In Roland Barthes par Roland Barthes (1975), the French critic encourages us to read his autobiographical essay as if spoken by a character in a novel. This gesture is usually considered one of the beginnings of the so-called "last Barthes", a period marked by an explicit volition for his work to tend to the novelization. A few years later, in the Leçon (1978) delivered in 1977-, he considers himself an "uncertain subject" for having only written essays during his career. The purpose of this paper is to read La Chambre claire's (1980) writing on the horizon of this double tension. On the one hand, the novelistic pole of said tension, together with Barthes' own postulates about the eminently realistic character of all literature, allows us to inquire about the way in which the realistic mimesis is used in the Barthesian book on photography, through certain contributions from Walter Benjamin (2007). On the other hand, the essayistic pole, considered as having the impulse of formulating a true critical thought, invokes the need of attending to the formal dimension of the book (in the Adornian sense of the expression [Cfr. 2013]). Both lines of research shed light on the question of the medium or the mediation understood as the core of the tension between novel and essay.

KEYwORDS: form, essay, novel, Barthes, Benjamin, Adorno.

\footnotetext{
${ }^{1}$ Licenciado en Letras por la Universidad Nacional de Rosario (UNR). Actualmente es becario doctoral por Agencia-Foncyt en el proyecto de investigación "Cómo se cuenta una vida. Escrituras e intimidad en la literatura latinoamericana contemporánea" (IECH-UNR) y cursa el Doctorado en Literatura y Estudios Críticos con la dirección de la Dra. Judith Podlubne y la co-dirección de la Dra. Julieta Yelin. Su proyecto se titula "Las 'vidas escritas' de Jorge Luis Borges en la primera década del siglo XXI". Además, se desempeña como ayudante de $2^{\circ}$ categoría en la cátedra Análisis del Texto, de la que forma parte desde 2015, y de la cátedra Análisis y Crítica II, desde el 2018.
} 


\section{Criação \&}

\section{Primer momento}

Uno de los comienzos indisputables del ensayo se puede ubicar en la figura de Michel de Montaigne - y sus Essais (1595²) -, por ser el responsable no solo de bautizar el género, sino también de sentar sus bases paradigmáticas. "Cada hombre lleva la forma entera de la humana condición" (2011, p. 724), dice en el segundo ensayo del Libro Tercero, para argumentar que el tema central de sus "ejercicios" es el "sí mismo" en su devenir de pruebas, accidentes y aprendizajes. A partir de los primeros párrafos de este ensayo, Erich Auerbach precisa aún más este tema (2014): lo que se ofrece a la lectura es el movimiento de un pensamiento en el devenir de la experiencia. Y un elemento crucial que atañe al ensayo es la búsqueda de un vínculo entre la exposición y la particularidad de aquello que quiere representar. En su análisis, Auerbach se detiene en la construcción del pensamiento que Montaigne plasma en el texto para darle los efectos de vida y movimiento necesarios con el fin de presentar el pensamiento en su "práctica efectividad" (2014, p. 269). En alguna zona lindante pero exterior a la autobiografía y el diario, el ensayo de Montaigne es profundamente realista, orientación que se evidencia en la persecución de una correspondencia entre el plano formal de la escritura ensayística y la naturaleza del objeto al que se aboca; esto es, un ser oscilante en el transcurrir de su experiencia. "Montaigne es algo nuevo" (2014, p. 274), indica Auerbach, "un realismo tan radical apenas lo ha conseguido nadie antes que él y muy pocos después" (2014, p. 283).

Desde luego, el análisis de Auerbach está orientado a la constatación de la hipótesis central de su libro Mímesis, esa que establece que el realismo moderno se erige sobre la aniquilación de la regla clásica de diferenciación de niveles representativos con el objeto de presentar asuntos cotidianos mediante un tratamiento serio e, incluso, trágico. De los dos párrafos del fragmento escogido por el filólogo alemán para su indagación, el segundo es el que le sirve como un ejemplo más de los tantos embates que, según indica, viene sufriendo la regulación clásica desde la aparición de la primera historia de Cristo hasta la literatura realista francesa de principios de siglo XIX como punto culminante. Sin embargo, el análisis que nos resulta más interesante es el realizado respecto del primero de los párrafos seleccionados, puesto que se detiene en la vitalidad de la expresión ensayística, es decir, en la dimensión formal del ensayo. Allí Auerbach reduce dicho párrafo a un silogismo ${ }^{3}$ para demostrar cómo Montaigne intenta poner sus premisas en acto en la

\footnotetext{
${ }^{2}$ Las diversas ediciones de los ensayos de Montaigne fueron publicadas entre 1580 y 1588 . Sobre la base de laúltima (que ya incluía el tercer libro), profusamente anotada por el autor, su hija intelectual Marie de Gourmay elabora de manera póstuma la edición, publicadaen 1595, hoy considerada definitiva. 3 "La dirección del pensamiento en el primer párrafo puede disponerse cómodamente en un silogismo: me describo a mí mismo; soy un ente en cambio constante y, por lo tanto, la descripción debe ajustarse a esta particularidad y cambiar, a su vez, de continuo" (AUERBACH, 2014, p. 267).
} 


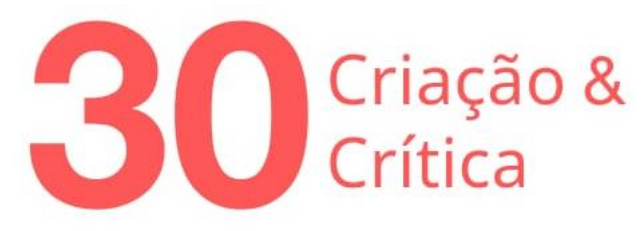

configuración de su escritura. También hace hincapié en los efectos dialógicos que produce la incorporación de una serie de rasgos propios de la conversación (como ser, omisiones, variaciones de una idea, carencia de conectores, etc.) y en el empleo de una modestia irónica que, a pesar de que iría en detrimento de su hipótesis central, aun así no solapa "una idea del hombre muy realista" (AUERBACH, 2014, p. 270), esto es, su naturaleza concebida como oscilante. Desde nuestra perspectiva, todos estos procedimientos formales, incluida la ironía, son fundamentales para una lectura realista del ensayo, en tanto su configuración es responsable de los efectos de vida - siendo la vida siempre oscilante e incierta- que el escritor busca como modo de entrar en relación, desde y en el lenguaje, con algo del orden de lo real.

En "En torno al realismo", Sandra Contreras reflexiona acerca de la literatura de César Aira con relación a lo que ella considera, con lucidez, el problema del realismo. Contreras indaga en la pulsión realista de Aira para redefinir la noción misma de realismo: abandonando el concepto tradicional que lo identifica como forma de representación de la realidad, se desplaza hacia una lectura que vaya al encuentro de "la invención de una forma y la forma de un deseo"; "la invención de un realismo" que alude "al deseo más íntimo de un arte con prisa por llegar a lo real" (CONTRERAS, 2018, p. 37) . La formulación de Contreras se desentiende de parámetros prescriptivos, como podrían ser los de Auerbach relativos a los temas y al tratamiento, para vincular la dimensión formal de la escritura con la pulsión deseante del escritor. Ese vínculo, como indica la ensayista rosarina, es alusivo y, por esa misma razón, siempre elusivo de una prescriptiva. Teniendo en cuenta estas consideraciones, los presupuestos y procedimientos clásicos de la representación realista, entre los que se encuentra la mímesis, requieren ser, si no deconstruidos, por lo menos desplazados hacia la transformación del vínculo entre lo real y el escritor.

A pesar de que los aportes mencionados de Contreras se producen siguiendo muy de cerca la obra airiana ${ }^{5}$, resultan aquí operativos para la lectura de la ensayística barthesiana, en tanto hay, hacia el final de la obra del crítico francés, una marcada voluntad de que su escritura tienda a la literatura, sobre todo si tenemos en cuenta que -como indica en la Lección inaugural - toda literatura es "absoluta y categóricamente realista" (BARTHES, 2015, p. 99), en el sentido de que "solo tiene a lo real como objeto de deseo" (2015, p. 101). Convencido de la inadecuación fundamental entre el lenguaje (como materia literaria) y lo real (como aquello que se quiere representar) - en otras palabras, la naturaleza digital del lenguaje-, Barthes

\footnotetext{
${ }^{4} \mathrm{~A}$ menos que se indique lo contrario, todos los resaltados de las citas textuales aparecen así en sus respectivos originales.

${ }^{5}$ Es importante notar, sin embargo, que Contreras no deja de lado los impulsos realistas de Barthes. En el capítulo "A modo de introducción. Derivas rancerianas hacia lo real", señala brevemente una omisión en la que cae Jacques Rancière cuando, discurriendo en una nota al pie sobre La cámara lúcida, se resiste a entrar en conversación con el sujeto de la escritura, ese que "tocado por lo real de la muerte, se entrega a la locura de un 'realismo absoluto' y se dispone a afrontar en ese éxtasis el despertar de la intratable realidad' (CONTRERAS, 2018, p. 28).
} 


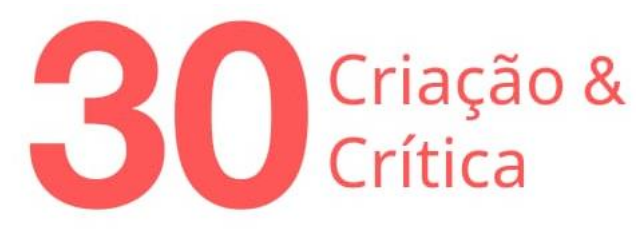

distingue en el realismo de toda literatura una dimensión profundamente irrealista, puesto que esta desea simultáneamente una adecuación (realismo) que sabe imposible (irrealismo): esto es lo que identificaría como su función utópica. En el marco de estos aportes, se vuelve pertinente la revisión de la noción de mímesis para ver cómo se puede adecuar a un deseo de (ir)real.

Una de esas revisiones está ligada a las especulaciones de Walter Benjamin. Durante 1933, en dos versiones de un texto abocado a lo que denomina la "facultad mimética" ${ }^{\circ}$ Benjamin inscribe la omnipresencia de dicha facultad en la naturaleza humana. Aunque presente también en el mundo no humano, el mimetismo se manifiesta en el ser humano de una forma muy propia: como tal, se encuentra en el juego infantil (en donde la imitación no se limita a referentes animados, sino también inanimados); en su devenir, la facultad mimética, que otrora tuviese una fuerte filiación con la búsqueda de semejanzas o correspondencias mágicas entre el micro y el macrocosmos (identificables en, por ejemplo, las danzas rituales, la lectura de las vísceras y la astrología), hoy tiene su mayor modelo en la capacidad semiótica del lenguaje (es decir, el establecimiento de fuertes asociaciones entre significante y significado/referente; asociaciones que quedarían abarcadas por lo que Benjamin denomina "semejanza no sensorial"). Lo que antes se daba en una duración (el rito de la danza, la recitación profética ante las vísceras, la interpretación del trabajo astral en el comportamiento humano), en el lenguaje, ese plexo de sentidos que transporta lo semiótico, se manifiesta de repente, como un chispazo. Respecto de esta filiación, Benjamin se pregunta si los cambios producidos se podrían considerar una decadencia de la facultad o simplemente una transformación. Como en muchos de los textos benjaminianos ${ }^{7}$, esta pregunta de tono melancólico ${ }^{8}$ es la que anuda lo que, en sus propios términos, podríamos llamar una imagen dialéctica: la construcción de una asociación intempestiva, ligadaala experiencia de un sujeto, de un pasado y un presente - el presente del pasado, que hace saltar el continuum de la historia - en un nudo de fuerzas con potencia crítica ${ }^{9}$. Culmina el segundo de los textos con esta conclusión:

\footnotetext{
${ }^{6}$ Según indican los editores de la obra completa, el primero de los textos, "Doctrina de lo semejante" (Obras libro II vol.1 208-213), parece haber sido escrito en febrero de 1933, mientras que "Sobre la facultad mimética" (Obras libro II vol.1213-216), durante el verano del mismo año.

7 "Experiencia y pobreza" (1973), El narrador (2008) y "La obra de arte en la época de su reproductibilidad técnica" (2009b) son algunos de los otros textos de Benjamin en los que se utiliza este procedimiento.

${ }^{8}$ Miguel Vedda, en su artículo "Anatomía de la melancolía: Acedia y alienación en Walter Benjamin y Siegfried Kracauer" (2014), hace referencia a la ambivalencia que el tratamiento benjaminiano hace de la melancolía en tanto el ensayista alemán se identifica con ella (como en el fragmento Agesilaus Santander) al mismo tiempo que la critica (como en "Melancolía de izquierda" y la Tesis sobre el concepto de historia).

${ }^{9}$ La noción benjaminiana de imagen dialéctica que aquí propongo se formula a partir de las lecturas de "Sobre el concepto de historia", "La obra de los pasajes (Convoluto N)" y el "Apéndice II" (que contiene los textos sobre Eduard Fuchs), todos incluidos en el libro La dialéctica en suspenso (2009a), además del ensayo "Walter Benjamin, escritor revolucionario" (2005) de Susan Buck-Morss en el libro homónimo.
} 


\section{Criação \&}

«Leer lo nunca escrito». Esa lectura es la más antigua: leer antes del lenguaje, a partir de las vísceras, o de las danzas o de las estrellas. Más adelante se utilizaron los intermediarios de una nueva lectura, como son las runas y los jeroglíficos. Y parece fácil suponer que éstas fueron las concretas estaciones a través de las cuales fue pasando, al ámbito de la escritura y el lenguaje, ese talento mimético que en otros tiempos era el fundamento de una praxis oculta. De este modo, el lenguaje vendría a ser el nivel más alto del comportamiento mimético, así como el archivo más perfecto de la semejanza no sensorial: un medio al que las fuerzas anteriores de producción y percepción mimética se fueron transvasando por completo hasta liquidar las de la magia (BENJAMIN, 2007, p. 216).

A la luz del interrogante planteado por la imagen dialéctica, parece haber en este cierre una especie de invitación: en ese río de tautologías que es el lenguaje, como diríamos con Barthe ${ }^{10}$, leer lo nunca escrito como en la antigüedad, leer antes del lenguaje o como si el lenguaje se desvaneciera, para, entre la escritura y la lectura - en su encuentro experiencial—, devolverle la fuerza de la magia en un chispazo (o darle, barthesianamente, un efecto de real). Una lectura atenta al vínculo siempre alusivo (y elusivo) entre deseo de real y forma se abocaría a la escucha, en esas asociaciones semióticas, de esos instantes intempestivos en los que algo de lo sensorial se quiere hacer presente. El lenguaje, por ser "el archivo más perfecto de la semejanza no sensorial" (BENJAMIN, 2007, p. 216), se ofrece a esa escucha como el medio a través del cual se podrían recuperar con fidelidad (pero no sin incertidumbre) esos instantes en los que algo puja por hacerse escuchar.

Aunque en un ámbito diferente —el de la fotografía-, Barthes también se detuvo a pensar en la magia como procedimiento con "talento mimético":

Los realistas, entre los que me cuento y me contaba ya cuando afirmaba que la Fotografía era una imagen sin código -incluso si, como es evidente, hay códigos que modifican su lectura-, no toman en absoluto la foto como una «copia» de lo real, sino como una emanación de lo real en el pasado: una magia, no un arte(2009, p. 137).

\footnotetext{
${ }^{10}$ En una de las primeras sesiones del curso La preparación de la novela (2005), Barthes, bajo la convicción de que la "literatura" se hace con la "vida" (las comillas son del original), se pregunta cómo hacer un relato o novela con la vida presente, a lo que se responde: "Se puede escribir el Presente anotándolo, a medida que 'cae' sobre nosotros o bajo nosotros (bajo nuestra mirada, nuestra escucha) (...). Por una parte, la Notación, la práctica de 'anotar': notatio. ¿En qué nivel se sitúa? ¿Nivel de lo 'real' (qué elegir), nivel del 'decir' (qué forma, qué producto para la Notatio)? Esta práctica, ¿qué implica del sentido, del tiempo, del instante, del decir? La Notatio aparece de antemano en la intersección problemática de un río de lenguaje, lenguaje ininterrumpido: la vida - que es texto a la vez encadenado, hilado, sucesivo, y texto superpuesto, histología de textos en capa, palimpsesto-, y de un gesto sagrado: marcar (aislar: sacrificio, chivo expiatorio, etc.). La Notación: ¿intersección problemática? Sí: es el problema del realismo lo que plantea la notación" (2005, p. 53-54).
} 


\section{Criação \&}

Esta magia mimética mediante la que se produce la certidumbre de algo real en la fotografía es semejante a lo que Barthes encuentra en el haiku (no como certeza, sino como impresión ${ }^{11}$ ), ligándolo, además, a "la esencia de la Notación" (2005, p. 55), ya que es en ella que se plantea el problema del realismo ${ }^{12}$. ¿Cómo, entonces, el haiku - en tanto hipóstasis de la práctica de la notación - utiliza la realidad como señuelo para producir un efecto de real (es decir, "el desvanecimiento del lenguaje en beneficio de una certeza de realidad" [2005, p. 117])? La lectura atenta de una serie de haikus le permite a Barthes identificar ciertos momentos en los que se produce dicho desvanecimiento: una contingencia pura (un hecho vivo) que, por medio del lenguaje, se eleva en una trascendencia (la abolición del hecho); el reconocimiento (repetición) de una sorpresa que da sensación de vida (algo que tuvo lugar una vez); el signo (de nuevo el reconocimiento) de algo no interpretable (ausencia de sentido), algo olvidado (no reprimido) o algo recordado (de índole proustiana) (BARTHES, 2005, p. 120-123). Allí, en esos instantes, se asocian intempestivamente, en la experiencia de un sujeto, elementos (el lenguaje, lo real) y tiempos (el pasado y el presente) heterogéneos que hacen saltar la continuidad del lenguaje (de su semiosis y su tiempo) a través del anudamiento crítico de fuerzas contrapuestas y simultáneas que tienden a la mutua anulación, al desvanecimiento. Esa magia imitativa es la que el escritor quiere configurar cuando, descendiendo por el lenguaje, tiene la impresión de deponerlo al producir el encuentro de una forma (la métrica, en el caso del haiku) con determinado fragmento de la realidad. Juntando Benjamin con Barthes, podríamos decir: recuperar lo nunca escrito, leer y escribir antes del lenguaje, como si en ese encuentro se produjera la magia química de la foto: esa es la pulsión que Barthes ensaya novelando en La cámara lúcida.

Desde la primera línea del libro, Barthes inscribe La cámara lúcida en el registro del relato; uno que narra en primera persona la búsqueda de la esencia de la fotografía. Ante el desorden del corpus (una serie de fotos que se resisten a la clasificación) y el dilema sobre el lenguaje apropiado para abordarlo (crítico o expresivo), el narrador de la primera parte se autofigura como un investigador irreverente: un héroe "inculto" de los años salvajes de la teoría que pretende convertir en razón su propia singularidad. La irreverencia queda manifiesta en varias oportunidades, como, por ejemplo, en "la resistencia furibunda a todo sistema reductor" (2009, p. 34), la denegación del corpus mediante la elección de "apenas algunas fotos" (2009, p. 34) que lo implicaran desde el cuerpo, y la audacia de adjudicarse la

\footnotetext{
11 "Mi propuesta es que el haiku se aproxima mucho al noema de la fotografía: 'Esto ha sido' (...); (...) el haiku trabaja una materia heterogénea (las palabras) para volverla fiable y aportar el efecto 'Esto ha sido'. Entonces, mi propuesta de trabajo es que el haiku da la impresión (no la certeza: urdoxa, noema de la fotografía) de que lo que enuncia tuvo lugar, absolutamente" (2005, p. 119-120).

12 "Considerar como posible (no irrisorio) una práctica de la notación es aceptar ya como posible un retorno (en espiral) del realismo literario", no en "sus connotaciones francesas o políticas", sino como "práctica de escritura que se ubica voluntariamente bajo la instancia del Señuelo-Realidad" (2005, p. 54).
} 
capacidad de formular el rasgo fundamental de la fotografía a partir de "algunos movimientos personales" (2009, p. 35). A pesar de la ambición del narrador, en esta primera parte es donde se ensayan las nociones de studium y punctum, ocurrencias que adquirieron gran relevancia en el ámbito de los estudios sobre la fotografía. Es notable cómo el libro barthesiano sobre la foto — que la tiene como pretexto- sigue suscitando lecturas que, recuperando los mencionados aportes en clave teórica, se resistan a ponerlos en juego con su dimensión narrativa; es decir, una lectura que no se atreve a problematizar la ingenuidad de sus presupuestos realistas ${ }^{13}$. No se trata aquí de negarle la sobrevida crítica a ninguna noción que pudiese adquirirla con independencia de su autor como función y, sobre todo, si se desata en la potencia de una escritura, sino de revisar los acuerdos de legibilidad que giran en torno al ensayo como género realista: hablar de los aportes de Barthes a la fotografía desde La cámara lúcida implica una creencia fiel en la palabra del narrador y desestima, al mismo tiempo, no solo sus gestos irónicos sino, lo que es más interesante aún, los elementos de una invención formal que responde al complejo deseo de aproximarse a lo real. La marcada inscripción en el registro del relato señala insistentemente su carácter de dramatización; de esta manera, cualquier aporte de tenor teórico que allí se presente no puede deslindarse de su cariz ficcional. Son, antes que nada, ficciones interpretativas de un hedonista errado que simula la ocurrencia de una propuesta de legibilidad fotográfica y cuya emergencia constituye la denegación de su búsqueda más íntima ${ }^{14}$. Como señala Alberto Giordano en "Literatura y poder" (2016, p. 64), la distinción studium/punctum se puede leer como la insistencia de una matriz de fuerzas diferenciales que Barthes viene ensayando, por lo menos, desde El placer del texto. De hecho, en esta primera parte, hay un sinnúmero de insistencias provenientes de la obra barthesiana: desde vocablos fetiche ("contingencia", "marcar", "cuajar", "cuerpo", "neutro", "grado cero", "para mí", etc.) hasta inquietudes que atraviesan el conjunto de sus búsquedas (el lenguaje deíctico, los sistemas reductores, el problema de la nominación, el teatro, la máscara, el trauma, el par denotación/connotación, entre muchas otras), pasando, desde luego, por el intertexto explícito e implícito con autores de su predilección. Hago hincapié en esto porque aquí encontramos no solo las

\footnotetext{
${ }^{13}$ Para referirse a algunos ejemplos de trabajos recientes que utilizan los aportes teóricos de punctum y studium sin ser relacionados con la dimensión narrativo-dramática, ver "Modos de ver, formas de pensar: una genealogía de la posvisión" de Josep Maria Català Domènech (2020) y "Fotografía, autobiografía y autoetnografía en Mitos: El Cuadrado del Tiempo" de Carmen Elena Viveros Celín (2020). Las lecturas de Tiphaine Samoyault (2015), en "Barthes y la fotografía", y de Bruno Crisorio y Silvina Sánchez (2020), en "Las piedras sobre el borde del círculo. Disquisiciones sobre La cámara lúcida de Roland Barthes y sus posibles vínculos con Fotos tuyas de Inés Ulanovsky", se muestran más sintonizadas con el sujeto enunciativo de la obra, aunque la falta de contextualización respecto de la formulación de estas nociones por parte del narrador-personaje quizás indique el lugar de una resistencia a la mencionada dimensión narrativo-dramática.

${ }^{14}$ La simulación es la noción que Barthes utiliza para reformular su propia versión de la noción de mímesis. En La preparación de la novela, la define como "una imitación reforzada" mediante la cual se penetra lo "verdadero" con lo "falso", lo "mismo" con lo "otro" (2005, p. 196).
} 


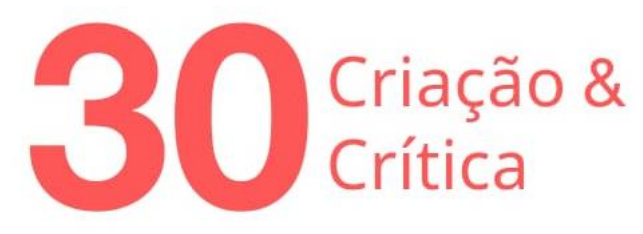

repeticiones habituales de cualquier escritor que, a medida que su obra crece, repertoriza un vocabulario, un conjunto de inquietudes y unos autores propios (elementos de un estilo, diríamos con el Barthes de El grado cero), sino también su dramatización como parte del relato: un collage de citas (propias y apropiadas, como nos enseña Bajtín) que muestra la discontinuidad de un narrador que se sustancia a medida que (se) enuncia.

La segunda parte reitera la inscripción narrativa mientras que la autofiguración se modifica: el fracaso se convirtió en la oportunidad de un reposicionamiento ante la búsqueda del genio fotográfico, de manera que ahora el narrador se identifica como un hijo en duelo que quisiera alguna vez escribir para sí mismo una pequeña obra sobre su madre. Si bien la esencia sigue siendo el objeto de la búsqueda, la apuesta se redobla en esta segunda parte porque, en tanto el objeto ahora está ligado a su madre y aunque las fotos que tiene de ella solo le ofrecen una autenticidad parcial, esa fragmentariedad le resulta insuficiente e incluso despierta un deseo de totalidad. Desde esta perspectiva, la segunda parte se presenta de entrada como la dialectización de la primera. En términos narrativos, el investigador irreverente que quiere encontrar el rasgo fundamental de la fotografía es ahora un hijo en tránsito de duelo que quiere escribir algo que lo ayude a sobrellevar la distancia irrevocable que le impone la muerte de su madre. En términos dramáticos, el deseo de totalidad es una negación de la inclinación por la parcialidad de la obra barthesiana hasta el momento. Si tomamos el punctum como la ocurrencia que la búsqueda de la esencia fotográfica encuentra en la primera parte, el hallazgo sigue siendo el avatar de una inquietud barthesiana que, como vimos, se viene trabajando desde al menos el comienzo de los años setenta (y que, por esa misma razón, le resulta insuficiente). Esta segunda parte radicaliza la esencia en totalidad al punto de convertirla en el germen de su propia destrucción doble: el eco de una propuesta de legibilidad (del medio, en este caso, el fotográfico) encuentra su negación en la experiencia total y directa de la confusión entre verdad y realidad (el noema).

Inmediatamente después de esta negación, justo en el momento en que se narra la aparición de la fotografía del invernadero, se perfilan tres figuras, en el sentido barthesiano de la expresión. La primera es la del patético enamorado (parágrafo 28), un sujeto atrapado en la imagen idealizada de la amada (en este caso, la madre). Bajo el emblema de la inocencia soberana, la madre se constituye en este discurso como modelo de civilidad y nobleza, portadora de una discreción distintiva, superviviente de una soledad infantil a través de su bondad idílica; todas estas caracterizaciones redundan en una paradoja débil, "la afirmación de una dulzura" (2009, p. 111). Solo un sujeto en estado de enamoramiento patético -adherido fuertemente a una imagen- puede olvidar por completo todo lo que sabe (lo que aprendió ensayando su obra) para dejarse llevar sin reparos por un ideario utópico: la totalidad ("justo una imagen pero una imagen justa" [112]) y "la ciencia imposible del ser único" (2009, p. 113). La segunda figura es la del indialéctico (parágrafo 29), un sujeto abismado en 


\section{Criação \&}

una serie de oposiciones sin resolución: los griegos que avanzan hacia atrás, la primera foto es la última, la pérdida y el reencuentro, la debilidad y la fortaleza, la madre/hija y la vieja/niña, lo particular y lo universal, la reproducción y la infecundidad, la escritura como pasado iniciático (la cultura Griega) y como proyecto final; a cada afirmación le corresponde una negación en una tensión irresoluble. En la primera parte, el narrador no les encontraba un orden a las fotos con las que quería trabajar, pero eso se decía a través del discurso ordenado de un sujeto siempre en control; aquí sucede lo opuesto, se acusa un ordenamiento de las fotos que suscita un profundo desorden discursivo. Finalmente, la tercera figura es la del encaprichado (parágrafos 30 y 31), un sujeto ciegamente apegado a una decisión arbitraria: "«sacar» toda la Fotografía (su «naturaleza») de la única foto que existía” para él (2009, p. 116) y, al mismo tiempo, no mostrarla para evitar la indiferencia ajena (es decir, para que los otros no arruinen su encanto); decisión que, a su vez, está inspirada por una fijación con la singularidad: la de su madre ("mi pena proviene del hecho de ser ella quien era" [2009, p. 119]), porque es una proyección de la suya propia ("no reducir jamás el sujeto que yo era" [2009, p. 118]). Este empecinamiento por respetar la originalidad de su sufrimiento al mismo tiempo que denuncia la imposibilidad de comprensión ajena también se le resiste; dejar por un momento de aferrarse a ese "círculo cerrado" entre él y la madre ${ }^{15}$ implicaría devolverlo a la comunidad (de sentido), mientras que el caprichoso está satisfecho con su insularidad. Lo que el capricho se niega a dar es lo que no puede darse porque nunca se tuvo; en esta recursividad viciosa reside una potencia de real que, anudada en las tres figuras, toma la forma de una pose que tiende a su encuentro ${ }^{16}$ : en este caso, la intensidad de una insistencia. Toda la narración de La cámara lúcida tiene su punto climático en la intensidad que el anudamiento de estas tres figuras produce gracias a la insistencia de sus gestos:

Aunque procedente de una religión sin imágenes en la que la Madre no es adorada (el protestantismo), pero formado sin duda culturalmente por el arte católico, ante la Foto del Invernadero yo me

\footnotetext{
${ }^{15}$ En el parágrafo 37, el narrador de La cámara lúcida dice: "Inmóvil, la Fotografía vuelve de la presentación hacia la retención. Puedo decirlo de otro modo. Veamos de nuevo la Foto del Invernadero. Me encuentro solo ante ella, con ella. El círculo está cerrado, no hay salida posible. Inmóvil, sufro. Carencia estéril, cruel: no puedo transformar mi dolor, no puedo dejar vagar la mirada; ninguna cultura acude a ayudarme a hablar de ese sufrimiento que vivo enteramente hasta la finitud de la imagen (es por ello por lo que, a pesar de sus códigos, yo no puedo leer una foto): la Fotografía -mi Fotografíaexiste sin cultura: cuando es dolorosa, nada en ella podrá transformar el dolor en duelo" (2009, p. 139). Ninguna cultura podrá ayudarlo a suspender la retención del círculo cerrado en tanto el narrador no quiera una salida.

${ }^{16}$ Como indica el propio Barthes en el parágrafo 33 de La cámara lúcida, la identificación de una pose responde a la intencionalidad de una lectura: “(...) la pose no es, no constituye aquí una actitud del blanco, como tampoco es una técnica del Operator, sino el término de una 'intención' de lectura: al mirar una foto incluyo fatalmente en mi mirada el pensamiento de aquel instante, por breve que fuese, en que una cosa real se encontró ante el ojo. Imputo la inmovilidad de la foto presente a la toma pasada, y esta detención es lo que constituye la pose" (2009, p. 123).
} 


\section{Criação \&}

abandonaba a la Imagen, a lo Imaginario. Podía, pues, comprender mi generalidad; pero, habiéndola comprendido, huía implacablemente de ella. En la Madre había un núcleo radiante, irreductible: mi madre. Todos pretenden que mi pena es mayor debido a que viví toda mi vida con ella; pero mi pena proviene del hecho de ser ella quien era; y es por ser ella quien era por lo que viví con ella (BARTHES, 2009, p. 118-119; el segundo subrayado me pertenece).

En esta notación reiterada se vislumbra la insistencia en toda su intensidad, esa que huye de la comunidad y que, a pesar del fugaz desdoblamiento subjetivo que produce -en tanto la repetición también propiciaría la ocasión de una escucha momentánea por la que podría suspenderse toda la persistencia-, continúa obstinándose. Toda la obra está abarcada por este gesto insistente, ya que está conformada por citas, repeticiones, reformulaciones, fragmentos en disposición paratáctica (que marcan un pulso reiterado), pero en el anudamiento de estas figuras es donde se muestra con mayor intensidad, porque marcan el profundo devenir niño del narrador (otra oposición dialéctica). Luego de esto, se nos ofrece el hallazgo del noema "Esto ha sido" y desde allí la intensidad decrece hacia la comprensión resignada de que la realidad es intratable. Con Benjamin, podríamos decir que el acercamiento a lo real de una experiencia a través de la escritura se produce solo a la manera del relámpago, un momento de iluminación intensa y fugaz de la que el texto es el trueno que sigue retumbando largamente (2009a, p. 87). Leer la pose como el punto de mayor intensidad de la insistencia es intentar recuperar algo de esa luz, como si fuera producto de laalquimia de la foto ocomo si pudiese desvanecer el lenguaje mágicamente. Parafraseando la definición de Fragmentos de un discurso amoroso (BARTHES, 2013c, p. 18), estas tres figuras muestran el gesto de un cuerpo sorprendido en estado de experimentación: los movimientos formales del discurso que gira en torno a estas figuras constituyen la invención que Barthes plantea como acercamiento a lo real de una aflicción no pasible de representación. Quizás, entonces, lo más real que se pueda ver de reojo en esta configuración sea la insistencia en su intensidad.

Como referí anteriormente, La cámara lúcida se mueve en dos niveles: el nivel narrativo despliega un relato sobre las aventuras de un protagonista que -como Barthes reivindica para el ensayista en "Las salidas del texto" - pide y protege la intrusión de sus valores en el discurso del saber; el nivel dramático, por su parte, teatraliza la obra volviendo al narrador uno de sus actores, lo que implica una forma de ataque al sujeto de la enunciación —el segundo de los pasos necesarios para sostener lo que Barthes denomina la "subjetividad del no-sujeto" (2013b, p. 352)-. Mediante estos movimientos liminares (como los objetos), se produce el desarrollo (la novelización) de algo que Barthes lee en cierto haiku analizado en La preparación de la novela, donde distingue el contorno de una "enunciación sutil"; esto es, una escena delineada a modo de cuadro realista con un actor que resulta ser también quien 


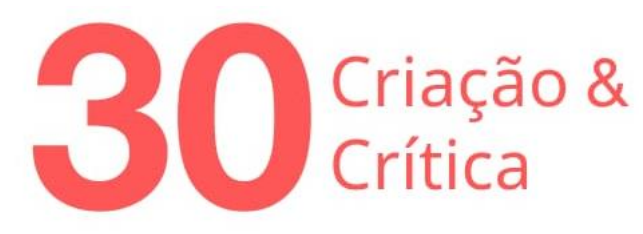

enuncia. El haiku es el siguiente: "Estación de lluvias. Miramos la lluvia. / Yo, y detrás de mí, de pie / Mi mujer" (2005, p. 110). El devenir actor del "yo" en el acto enunciativo atenta contra esa subjetivación, porque ese sujeto puede ver a su mujer y, al mismo tiempo, puede no verla. Es decir, no es que el sujeto de la enunciación no pueda ver a su mujer en su faceta de actor; al contrario, se permite no verla. Al asumir ese enceguecimiento voluntario, el sujeto atenta contra sí mismo — porque sabe que todo acto voluntario se produce gracias a un punto de fuga involuntario- en un acto de generosidad absoluta: se ofrece lo suficientemente incierto como para que su potencia vital adquiera vida en la lectura de una forma. Algo similar sucede en La cámara lúcida cuando el narrador deviene el patético niño enamorado, abismado en irresoluciones y profundamente caprichoso, que voluntariamente ofrece su ceguera de la obra escrita (toda su obra hasta ese momento) y, con ese gesto, se vuelve disponible a una lectura vivificante: una muerte (el desdoblamiento de un sujeto arrojado a la invidencia) antes de la Muerte (del autor como función y del individuo civil), una contingencia trascendente, como si quisiéramos leer antes del lenguaje.

Como apunta Auerbach a propósito de Montaigne, la cuestión del realismo atañe al ensayo desde su paradigmático comienzo renacentista. Según las reflexiones de Contreras, con el fin de que esta preocupación estética vuelva a tomar vigencia sin quedar atrapada en presupuestos que perjudiquen su eficacia crítica, es conveniente desplazarse de sus formulaciones tradicionales a una que permita poner en relación el autor con la realidad que quiere alcanzar a través de la escritura, siempre observando de cerca la complejidad de su problemática central: la mediación en tanto forma que vincula una invención con un deseo de aproximarse a lo real. Un acercamiento anoticiado de las dificultades que presupone la mediación deberá, al menos, volver a trazar los fundamentos de los conceptos que funcionan como su piedra angular e instalarlos, siguiendo a Barthes, en lo que constituye el medio -la forma - por excelencia para todo lo relacionado no solo con la literatura, sino, también, con el ser humano; es decir, el lenguaje en su dimensión configurativa. Si vemos en retrospectiva la obra barthesiana, podemos identificar la operación reiterada de hacer pasar la literatura por una problemática de lenguaje. Esta estrategia permitiría trascender los límites estrechos de la institución literaria que la alberga para ser considerada desde el punto de vista que la entendiese como una manifestación artística del ser humano que lo informa, alusiva y elusivamente, de algo íntimamente constitutivo de sí mismo. Desde esas nuevas coordenadas, el problema del realismo en Barthes interroga el modo en que la singularidad de lo real en tanto experiencia subjetiva pueda burlar, mediante la invención formal de una escritura, su reducción indefectible en el lenguaje. Esta inquietud se pone a prueba en la escritura de La cámara lúcida mediante los efectos que produce el anudamiento de las figuras que vimos anteriormente y, además, mediante la tensión simultánea que ejerce sobre la dimensión formal en dirección de la novela y el ensayo. Si la primera quiere alcanzar lo real de una experiencia sin las devaluaciones operadas por el lenguaje como medio, 


\section{Criação \&}

la segunda aboga por un pensamiento realmente crítico que evada su poder gregario. Tendiendo a este fin, el polo ensayístico de La cámara lúcida le imprime una configuración a la obra mediante la postulación de un lenguaje crítico y su concurrente puesta en crisis; es decir, genera una recursividad metacrítica con el propósito de no caer en las impotencias de un metalenguaje.

\section{Segundo momento}

En 1970, de manera póstuma, se publica Teoría estética de Theodor W. Adorno, una recopilación de una serie de borradores en los que el filósofo y compositor alemán trabajó entre 1956 y 1969. Según sus formulaciones, ante la evidente esterilidad de la filosofía en un contexto de posguerra y fascismo, el arte y la teoría estética son formas superadoras que pueden poner en práctica un pensamiento verdaderamente crítico, es decir, uno que ponga de manifiesto las contradicciones de la sociedad moderna. "La definición de aquello en que el arte pueda consistir siempre estará predeterminada por aquello que alguna vez fue, pero solo adquiere legitimidad por aquello que ha llegado a ser y más aún por aquello que quiere ser y quizás pueda ser" (ADORNO, 2014, p. 11). Desde un comienzo de la obra, el énfasis está puesto en el devenir de lo artístico, una cierta negación de su origen y un deseo volcado al futuro. Unas líneas después, aventura la siguiente definición:

La perspectiva hegeliana de una posible muerte del arte está de acuerdo con su mismo devenir. El que lo considerase perecedero y al mismo tiempo lo incluyese en el espíritu absoluto armoniza bien con el doble carácter de su sistema, pero da pie a una consecuencia que él nunca habría deducido: el contenido del arte, lo absoluto de él según su concepción, no se agota en las dimensiones de su vida y muerte. El arte podría tener su contenido en su propia transitoriedad. (...) [E]I arte no es solo arte sino también algo extraño y contrapuesto a él mismo. En su concepto mismo está escondido el fermento que acabará con él (ADORNO, 2014, p. 12-13).

La materia del arte es su mutabilidad, por eso, la música es la que mejor representa su característica definitoria, en tanto es el "estrictísimo y sin embargo aconceptual arte de la transición" (ADORNO, 2013, p. 32). Es su condición de forma pura la que pone de manifiesto no solo el devenir, sino también -y sobre todo- la contradicción en su carácter irresoluble: el movimiento vital de su muerte periódica.

Dadas sus preocupaciones por formular un pensamiento realmente crítico, no causa sorpresa que Adorno también interrogara la escritura. En el Epílogo que agrega Rolf Tiederman —quien, junto a Gretel Adorno (la viuda de Theodor), fuesen los responsables de la primera edición de Teoría estética-, se incluye un apartado 


\section{Criação \&}

dedicado a la organización del texto y la relación entre la exposición y lo expuesto. Allí se hace referencia a fragmentos de correspondencia de Adorno en los que se reflexiona sobre las dificultades presentes a la hora de que el pensamiento crítico se manifestase no solo desde el contenido, sino también desde la forma. Cito un fragmento de sus cartas:

Se trata simplemente de que de mi teorema de que en filosofía no hay nada 'primero' se sigue que no se puede construir un nexo argumentativo siguiendo los pasos habituales, sino que hay que montar el todo a partir de una serie de complejos parciales que tienen el mismo peso y están ordenados de manera concéntrica, en el mismo nivel; su constelación, no su sucesión, tiene que producir la idea (ADORNO, 2014, p. 482).

El dibujo, entonces, para Adorno, es el de los círculos concéntricos cuyo centro (idea) es producido a partir de la constelación de complejos parciales en disposición paratáctica. Como apunta Tiederman, este trazado no terminaba de satisfacer las exigencias críticas de Adorno, que pensaba reorganizar su obra empresa que se vio truncada por la muerte-, en tanto la disposición paratáctica era también aporética: exigía una solución cuyo carácter irresoluble no comportaba dudas para Adorno.

A pesar de ser un trabajo en proceso (y, quizás, por esa misma razón), retengo la imagen de la escritura en círculos concéntricos, porque resulta útil como otro medio de ingreso a La cámara lúcida de Roland Barthes. El problema crítico de la escritura en Adorno entra en consonancia con el trabajo barthesiano en tanto, para el ensayista francés, la figura escrituraria que pudiese poner de manifiesto su búsqueda crítica es el laberinto; más específicamente, el minoico, que define de la siguiente manera: "se puede obtener un laberinto minoico (sin desniveles sistemáticos) interrumpiendo con una o dos uniones una serie de círculos concéntricos" (BARTHES, 2005, p. 171) ${ }^{17}$. En La cámara lúcida, la apelación al laberinto se hace explícita en la invocación a un aforismo de Friedrich Nietzsche: "Un hombre laberíntico jamás busca la verdad, sino únicamente su Ariadna" (BARTHES, 2009, p. 116). Pero lo laberíntico también se manifiesta en la organización del libro. En su primera parte, la vía de entrada es la anécdota de la foto de Jerónimo Bonaparte; las dos direcciones posibles del círculo exterior se dividen entre la Fotografía y unas fotografías (un corpus versus algunos cuerpos); el círculo siguiente bifurca las vías de lo clasificable y lo inclasificable en la fotografía; el contiguo se dirime entre la voz de la ciencia y la voz salvaje; a continuación, un trinomio, Operator, Spectrum y Spectator, que rápidamente se

\footnotetext{
${ }^{17}$ La definición proviene de la sesión con la que Barthes abrió un ciclo de conferencias, titulado "La metáfora del laberinto", que se dictó entre el 2 de diciembre de 1978 y el 10 de marzo de 1979 (mismo período en que se dictó la primera parte del seminario "La preparación de la novela").
} 


\section{Criação \&}

convierte en binomio (como el de los círculos anteriores); de allí, pasamos a la famosa dicotomía Studium/Punctum; y, finalmente, en el último fragmento de la primera parte, desembocamos en un callejón sin salida: habíamos estado recorriendo el laberinto hedonista de las ilusiones perfectas. "Debía descender todavía más en mí mismo para encontrar lo evidente de la Fotografía" (BARTHES, 2009, p. 100; el subrayado me pertenece). Como vimos el movimiento de descenso es significativo porque conjuga varias alusiones además de las ya apuntadas: por un lado, podríamos calificar al descenso como dantesco e, incluso, órfico; por otro, indica un pasaje: ya no estamos en el laberinto minoico, sino que comenzamos a transitar el laberinto egipcio, esto es, una tumba-monumento ${ }^{18}$. La segunda parte también comienza con el relato de una anécdota, la tarde en que estaba viendo fotos de la madre; el debate ahora es entre esas fotos (las de la madre) y, prontamente, la fotografía (nótese la minúscula inicial, que difiere de la Fotografía en la primera parte); a continuación el debate gira en torno a las instituciones generalizadoras (Familia, Madre) frente al individuo del orden de lo "irremplazable"; seguidamente, las voces de la trivialidad y la singularidad; poco después, la enunciación del noema "Esto ha sido" y la identificación de un nuevo punctum: el Tiempo (como énfasis del noema: la intensidad). Aquí aparece una serie de desplazamientos que parten del punctum, no para avanzar sobre su especificidad, sino para retroceder en su significación: se desplaza replegándose. El repliegue insiste en numerosas oportunidades ya hacia el cierre del libro: en la postulación del "aire" como "suplemento inflexible de la identidad", su cualidad exclamativa que señala el "fin de todo lenguaje" ("iEs esto!"), un "satori en el que las palabras desfallecen"; en la locura como la unión de la realidad con la verdad; en la música de la Piedad como variación del tema de la locura (el episodio aludido en el que Nietzsche corre a abrazar a un caballo maltratado es el que se volvería el mito del comienzo de su locura ${ }^{19}$ ); en el éxtasis fotográfico, en el que el Tiempo se retrotrae a cualquier crono-lógica histórica para poner frente a la conciencia la realidad absoluta; y, finalmente, en la intratable realidad. De esa manera, la segunda parte podría pensarse también como la vía de regreso por el laberinto: desandarlo para volver al inicio (que no es su salida).

Ahora bien, la verdad del laberinto, según Barthes, radica en su carácter lúdico: su cariz Irrisorio (2005, p. 180). Puedo citar varios elementos de esta índole presentes en La cámara lúcida. El primero de todos, que persiste por casi la mayor parte del libro, es la explícita búsqueda de una esencia; en este caso, es la de la Fotografía, pero, en Barthes, cualquier empresa semejante, aunque solo perdure estrictamente en su momento inicial, es, por lo menos, una provocación, sobre todo, si se postula como motivación fundante de sus notas, en tanto su obra entera atestigua

\footnotetext{
${ }^{18}$ La alusión a los laberintos egipcios como tumbas es postulada por el mismo Barthes: "Para nosotros: Laberinto $=$ Grecia. Pero hay diseños laberínticos en los sellos egipcios. Laberinto egipcio: siempre asociado a la tumba faraónica, que es un laberinto (en el centro, los despojos del Rey)" (2005, p. 169). ${ }^{19}$ El mismo Nietzsche que había denostado el sentimiento de piedad como heredero de una moral cristiana que ponía límites a las potencias del hombre creador.
} 


\section{Criação \&}

su rechazo por cualquier metafísica que invalidase la potencia de lo singular. Como veremos más adelante, la búsqueda de este genio de la fotografía es precisamente lo que más lo aleja de ella; en esta inversión (de Autor a narrador) se manifiesta el carácter burlesco del laberinto: la búsqueda de la esencia es la trampa que lo obliga a perderse en él ("tan bien hecho, perfilado, — dice Barthes sobre el laberinto- que uno desemboca en un fracaso" [2005, p. 172]). Apunto dos elementos más: por un lado, la inversión de la madre en hija, que junto a la foto de Nadar (y la confusión entre madre o esposa), producen lo que se podría llamar la carnavalización de la figura materna ante el narrador (inversión que tiene un antecedente fuerte en la primera de las fichas del Diario de duelo [26 de octubre de 1977, el día después de la muerte de la madre]); por otro lado, otra carnavalización del tiempo, presente en la caracterización de la foto del joven Lewis Payne, en la que pasado y futuro son contemporáneos en el presente y que, ante la Foto del Invernadero, se transforma en una catástrofe (caotización del presente en la que el tiempo como duración se anula: esto también tiene un antecedente en la entrada del diario del 29 de noviembre de 1977, donde, además, se apela a John Cage —lo enuncio aquí para tratarlo más adelante-). Todos estos elementos mencionados pueden agruparse bajo el concepto de carnavalización, que traigo precisamente de los trabajos de Kristeva sobre la obra de Bajtín, y que me permiten afiliar otra vez La cámara lúcida al género novelesco para dar cuenta del impacto totalizador de esta caotización que impregna, incluso, el estatuto genérico del libro. Se vuelve a imponer la pregunta: ¿es ensayo o es novela? Seguramente los dos o, quizás, ninguno de ellos: lo que Barthes, según su ensayo "Mucho tiempo...", denominaría una "tercera forma" (2013b, p. 396). En ese mismo texto, a partir de la encrucijada proustiana, a la alternancia genérica Barthes le hace corresponder una alternancia estructural: el camino del ensayo sería el de la metáfora, mientras que el de la novela sería la metonimia; interpretación, por un lado, y fabulación, por el otro. En La cámara lúcida, esto se aprecia en los mencionados desplazamientos que se producen en la segunda parte suscitados a partir del punctum: la exploración de cada nominación (punctum, detalle, Tiempo, el aire, la locura, la música de la piedad, el éxtasis fotográfico, la realidad intratable) avanza, con excepción de la última, mediante una metafórica interpretativa, cuyo hilo conductor radica en una metonímica fabulativa. Al igual que En busca del tiempo perdido, lo que se narra allí no es una obra, sino el deseo de escribir una obra: el patetismo de la encrucijada se muestra en la búsqueda de una forma otra que recoja a la vez la novela del sufrimiento del narrador y lo trascienda ensayísticamente.

En la última sesión de "La metáfora del laberinto", Barthes presenta dos respuestas, una afectiva y otra intelectual, a la pregunta "¿Qué es el laberinto para mí?" (2005, p. 180) —de tinte nietzscheano- que se hace al cierre del ciclo de conferencias. En principio, el laberinto suscita una única resonancia afectiva: la imposibilidad de llegar a la madre como forma típica de la pesadilla infantil (el niño perdido, abandonado); a lo que le introduce una ambivalencia: la posibilidad de que el 


\section{Criação \&}

laberinto sea una protección (la identificación puede ser con Teseo o con Minos, respectivamente). En La cámara lúcida, la trayectoria de toda la primera parte marca el ingreso a lo más profundo de ese laberinto imaginario que resultó ser la respuesta que Barthes dio frente a la fotografía, porque la búsqueda de su esencia se transformó en la esencialización de una experiencia ${ }^{20}$; ante la pérdida de la experiencia —es decir, su conversión en vivencia-, sobreviene la "sobre-clausura tranquilizadora" (2005, p. 181). La segunda parte, en cambio, como adelanté anteriormente, hace el camino inverso: vuelve sobre sus propios pasos, se desplaza replegándose, hacia el inicio del laberinto —que, reitero, no es su salida — para volver a la experiencia en su naturaleza más punzante: la angustia muda de la pérdida de la madre, es decir, la realidad en tanto intratable. Para un escritor, perderse en el laberinto es inevitable, a sabiendas de que la recuperación de la experiencia solo se produce en su desandar — con la suerte $o$ el azar de su lado, en tanto el experimentante nunca es agente de la experiencia- A esta altura es evidente que, para Barthes, el laberinto lo implica en tanto trata el lenguaje de manera indirecta (Cfr. 2005, p. 175) y que, para el hombre, no hay salida del laberinto, de la misma manera que no hay un afuera del lenguaje.

En cuanto a la respuesta que identifica como intelectual, Barthes trae a colación una definición que Octave Mannoni propuso en su conferencia denominada "Labyrinthe et énonciation" a propósito de la literariedad: "lo que no presenta ninguna transformación posible" (BARTHES, 2005, p. 181). Barthes identifica en los aportes de Mannoni una inquietud acerca de la legibilidad/ilegibilidad que precisa como "las fugas de la legibilidad (en el sentido perspectivista del término)" (2005, p. 181). Esto le permite hacer una nueva pregunta acerca del laberinto: ¿dónde comienza la legibilidad? Es decir, ¿dónde comienza, entonces, un laberinto? "Nos acercamos a la epistemología de las consistencias progresivas, de los umbrales, de las intensidades: la viscosidad de las formas" (2005, p. 181). Aquí me resulta conveniente transferir la inquietud del dominio de la lectura hacia el de la escritura. Lo que no permite transformación, para el escritor, es precisamente la experiencia: aquello de carácter impersonal e infantil, fuera del tiempoy ellenguaje. Cualquier intento de transformación, cualquier avance por la viscosidad del laberinto, no podrá más que arruinar su singularidad contingente y, sin embargo, el escritor no podrá evitarlo. Su virtud y su condena estriban en el deseo utópico, como el deseo de una esencia, de alcanzar la

\footnotetext{
${ }^{20}$ En términos de Walter Benjamin, sería una experiencia propiamente dicha (Erfahrung), devenida en vivencia (Erlebniss). En "Sobre algunos temas en Baudelaire" (1972), Benjamin pone en relación el término Erfahrung con Erlebniss a fin de hacer manifiesta la heterogeneidad de la noción de experiencia. En el marco de una reflexión acerca del papel amortiguador —anestésico, según Susan Buck-Morssde la consciencia (en tanto sirve como protección contra estímulos que pudiesen producir un shock), Erlebniss aludiría a las "experiencias vividas" como acontecimientos a cuyo desarrollo la consciencia pudo atender, mientras que Erfahrung haría referencia a la experiencia en cuanto que no fue vivida conscientemente. Las experiencias vividas, de acuerdo con la terminología empleada por Benjamin, serían el producto de la esterilización de un acontecimiento, puesto que, para que pueda ser incorporado al inventario de recuerdos conscientes, debe despojarlo de su carácter traumático.
} 


\section{Criação \&}

realidad mediante un material radicalmente diferente a la naturaleza de aquello que se quiere alcanzar. Por estarazón, la realidad es caracterizada como intratable; mejores términos serían inflexible o intransigente. En este sentido, la cadena de nominación metonímicay sus correspondientes explosiones metafóricas conforman constelaciones (es decir, trazos imaginarios) cuya proyección global remite constantemente a los puntos de fuga por donde se filtra la legibilidad opasibilidad transformativa.

Otra serie de fórmulas utiliza la noción de fuga como proceso constructivo: son las que se dirimen entre los pares opositivos movimiento/detención, visible/invisible y vida/muerte. Veamos algunos ejemplos:

En la Fotografía, la inmovilización del Tiempo solo se da de un modo excesivo, monstruoso: el Tiempo se encuentra atascado (...). El que la Foto sea 'moderna', se encuentre mezclada a nuestra cotidianeidad más ardiente, no impide que haya en ella como un punto enigmático de inactualidad, una extraña estasis, la esencia misma de una detención (...) (BARTHES, 2009, p. 140).

No es que la detención tenga lugar a pesar e independientemente de la modernidad — que aquí tiene el sentido de la agitación de lo ardiente; es decir, el movimiento-, sino que dicha agitación solo es posible porque hay un punto enigmático cuya naturaleza misma es la detención (es decir, arrêt, suspensión, la unión mística con Dios). La condición de existencia del movimiento es precisamente la detención, materia fundante de la realidad dinámica, pero inaprensible para la consciencia - aquí sigo los postulados de Baruch Spinoza cuando establece que la consciencia solo sabe de efectos, puesto que las causas le están vedadas ${ }^{21}$. Sigamos con otro ejemplo:

Ahora bien, ante millares de fotos, incluidas aquellas que poseen un buen studium, no siento ningún campo ciego: todo lo que ocurre en el

\footnotetext{
${ }^{21}$ La teoría sobre lo ilusorio de la consciencia que solo conoce de efectos la recupero de Spinoza: Filosofía práctica (2006) de Gilles Deleuze. Específicamente, del capítulo denominado "Sobre la diferencia entre la ética y una moral". Teniendo como interlocutor el principio tradicional de la Moral (empresa que pretende que la conciencia domine las pasiones), Spinoza formula una de sus tesis teóricas fuertes relativa al paralelismo entre el cuerpo y el espíritu; alejándose de cualquier causalidad o supremacía entre uno y otro, propone que lo que es acción en el alma también lo es en el cuerpo y, por su parte, viceversa. En este sentido, lo concerniente al cuerpo supera el conocimiento que tenemos de él, mientras que, análogamente, el pensamiento supera la conciencia que de él tenemos. La significación práctica de la tesis indica que es necesario conocer los poderes del cuerpo para descubrir los del espíritu. Por otro lado, la conciencia - denuncia Spinoza- es el lugar natural de una ilusión, porque solo puede recoger los efectos e ignora por completo las causas. Cuando un cuerpo se encuentra con otro, o una idea se encuentra con otra, se producen relaciones de composición (potenciación) o descomposición (debilitamiento). El orden de las causas, en este sentido, es un orden de composición y descomposición de relaciones que afectan a la naturaleza entera: nuestra conciencia, de eso, solo conoce los efectos.
} 


\section{Criação \&}

interior del marco muere totalmente una vez franqueado este mismo marco. Cuando se define la Foto como una imagen inmóvil, no se quiere sólo decir que los personajes que aquélla representa no se mueven; quiere decir que no se salen: están anestesiados y clavados, como las mariposas. No obstante, desde el momento en que hay punctum, se crea (se intuye) un campo ciego (...) (BARTHES, 2009, p. 95).

Aquí vemos nuevamente cómo se replica el proceso constructivo del punto de fuga: el punctum de la foto es el indicio (la intuición) de que lo visible, aquello del orden de los efectos, solo es posible gracias a la existencia inaprensible de lo invisible, por ser del orden de las causas. Dicho de otra manera, ¿dónde comienza lo visible? En su fuga, que es lo invisible. En consonancia con el par movimiento/detención, termino con el par opositivo vida/muerte:

(...) si la Foto me parece estar más próxima al Teatro, es gracias a un mediador singular (quizá yo sea el único en verlo así): la Muerte. Es conocida la relación original del Teatro con el culto de los Muertos: los primeros actores se destacaban de la sociedad representando el papel de Muertos: maquillarse suponía designarse como un cuerpo vivo y muerto al mismo tiempo (...). Y esta misma relación es la que encuentro en la Foto; por viviente que nos esforcemos en concebirla (y esta pasión por "sacar vivo» no puede ser más que la denegación mítica de un malestar de muerte), la Foto es como un teatro primitivo, como un Cuadro Viviente, la figuración del aspecto inmóvil y pintarrajeado bajo el cual vemos a los muertos (BARTHES, 2009, p. 65).

En tanto Barthes opone pasión de vida frente a malestar de muerte, la denegación aludida bien puede ser de índole cultural (y, por eso, mítica). Pero, en un sentido más estructural, creo yo que allí se trata de la naturaleza de lo humano, algo que está en su constitución misma: la muerte se afirma radicalmente sobre su ausencia de registro. Como sabemos, el sujeto se produce en y por el lenguaje; su muerte, dada la condición de seres hablantes que somos, carece de representación posible y, sin embargo, es la denegación de ese "terror sin nombre" o "angustia inconcebible" la piedra angular en la que se erige el lenguaje. El lenguaje, en este sentido, es un teatro en el que las máscaras vivientes señalan la inconcebible muerte que las constituye. Si bien la representación de la muerte es imposible para la vida del sujeto, es imprescindible ya que es su condición de existencia. Como "los objetos laminares de los que no podemos separar dos láminas sin destruirlos" (BARTHES, 2009, p. 31), lo constitutivo de la vida es la muerte, así como lo es la ilegibilidad de la legibilidad, el inicio del laberinto y, como veremos a continuación, en términos adornianos, lo absoluto del lenguaje. 


\section{Criação \&}

Podríamos concluir con algunas ideas de Adorno acerca de la relación entre música y lenguaje:

El lenguaje denotativo querría decir de manera mediada lo absoluto, y este se le escapa en cada intención individual, deja atrás a cada uno como definitivamente detrás de sí. La música da en él inmediatamente, pero en el mismo instante se lo oscurece, del mismo modo que la luz demasiado fuerte ciega unos ojos que ya no pueden ver lo totalmente visible. La música acaba por parecerse una vez más al lenguaje en la medida en que, en cuanto al borde del fracaso, es enviada, lo mismo que el lenguaje denotativo, a la odisea de la mediación infinita a fin de traer a casa lo imposible (2000, p. 28).

Como nos recuerda Jorge Luis Borges en "La muralla y los libros" (Otras inquisiciones, 2016), ya Walter Pater, hacia fines del S. XIX, enunciaba que todas las artes deben tender a la condición de la música. Ahora bien, desde la perspectiva adorniana, la música, a pesar de que cuente con la posibilidad de un acceso más directo -aunque fugaz - a la realidad intratable (lo absoluto en Adorno), sigue adoleciendo del mismo mal que atormenta al lenguaje: la mediación infinita. Se me presenta inmediatamente la siguiente inquietud: si las artes deben tender a la música (puesto que forma y contenido, como también nos explica Borges, son coincidentes), ¿a qué debe tender la música? La obra de Cage, "4'33"', puede servir para contestar esa pregunta. Allí, el intérprete de la obra tiene la indicación de guardar silencio (Tacet) sin tocar su instrumento durante el tiempo indicado en su título. Por lo general, se piensa que el quid de la pieza radica en la interpretación de "cuatro minutos y treinta y tres segundos de silencio"; sin embargo, algunos teóricos consideran que el material sonoro de la obra lo componen los ruidos ambientales que el espectador escucha durante ese tiempo. Esta segunda concepción resulta un poco más acertada, aunque requiera de alguna precisión. Es posible "hacer silencio", en el sentido de tomar los recaudos posibles para abstenerse de emitir sonido alguno, pero el silencio "en sí" no existe para nosotros (análogamente, es posible abstenerse de hablar sin que esto implique la anulación del lenguaje). Lo que la obra de Cage, según esta perspectiva, pone de manifiesto es que la música no es posible sin el silencio como su condición de existencia y, aun así, si quiere tener un contacto directo con lo absoluto, no puede más que embarcarse en la odisea de traer a casa lo imposible, es decir, el silencio. Si todas las artes deben tender a la condición de la música, entonces, la música debe tender a la condición del silencio. Esta formulación circular es la que conformaría el laberinto de La cámara lúcida. Lo que comenzó con un asombro silencioso (la soledad de la afección ante la foto de Jerónimo Bonaparte) termina, habiendo mutado, con un regreso al silencio que señala la realidad intratable. 


\section{Criação \&}

Apunté alguna vez que la ensayística de Barthes se manifiesta gracias a la afirmación de una ética de la evasión: un movimiento del pensamiento que busca utópicamente una correspondencia análoga con una pulsión corporal y cuya inscripción digital se transforma en una configuración del decir (BOHNHOFF, 2019, p. 132). Según lo hasta aquí expuesto, se vuelve necesario ampliar apenas esta idea: lo evasivo de su ética entra en consonancia con la dinámica laberíntica del lenguaje y de algo relativo a la condición definitoria de lo humano. Por un lado, la inflexibilidad de lo absoluto impide toda transformación articulable y, al mismo tiempo, el deseo artístico (humano) se empeña en alcanzar lo absoluto, aunque sea una empresa utópica. Lo real evade al lenguaje de la misma manera que el lenguaje se evade de lo real. La ética de la evasión es la que pone de manifiesto, entonces, una condición netamente humana.

\section{Bibliografía}

ADORNO, T. "Música, lenguaje y su relación en la composición actual [Fragmento sobre la música y el lenguaje]". In: Sobre la música. Trad. Marta Tafalla González. Barcelona: Ediciones Paidós Ibérica I.C.E./U.A.B, 2000.

ADORNO, T. "El ensayo como forma". In: Notas sobre literatura. Obra completa, 11. Trad. Alfredo Brotons Muñoz. Madrid: Editorial Akal, 2013.

ADORNO, T. Teoría estética. Obra completa, 7. Trad. Jorge Navarro Pérez. Madrid: Editorial Akal, 2014.

AUERBACH, E. "L'humaine condition". In: Mimesis. La representación de la realidad en la literatura occidental. Trad. Ignacio Villanueva y Eugenio Ímaz. Buenos Aires: Fondo de Cultura Económica, 2014.

BARTHES, R. Roland Barthes por Roland Barthes. Trad. Alan Pauls. Buenos Aires: Eterna Cadencia Editora, 2018.

BARTHES, R. El placer del texto y Lección inaugural. Trad. Nicolás Rosa y Oscar Terán. Buenos Aires: Siglo Veintiuno Editores, 2015.

BARTHES, R. El grado cero de la escritura y nuevos ensayos críticos. Trad. Nicolás Rosa y Patricia Wilson. Buenos Aires: Siglo Veintiuno Editores, 2013a.

BARTHES, R. El susurro del lenguaje. Más allá de la palabra y la escritura. Trad. Carlos Fernández Medrano. Buenos Aires: Editorial Paidós, 2013b.

BARTHES, R. Fragmentos de un discurso amoroso. Trad. Eduardo Molina. Buenos Aires: Siglo Veintiuno Editores, 2013c.

BARTHES, R. La cámara lúcida. Nota sobre la fotografía. Trad. Joaquim SalaSanahuja. Buenos Aires: Editorial Paidós, 2009.

BARTHES, R. La preparación de la novela. Notas de cursos y seminarios en el Collège de France, 1978-1979 y 1979-1980. Trad. Patricia Willson. México: Siglo XXI Editores, 2005.

BENJAMIN, W. La dialéctica en suspenso. Trad. Pablo Oyarzún Robles. Santiago de Chile: LOM Ediciones, 2009a.

BENJAMIN, W. "La obra de arte en la época de su reproductibilidad técnica". In: Estética y política. Trad. Julián Fava y Tomás Bartoletti. Buenos Aires: Editorial Las cuarenta, 2009b. 


\section{Criação \&}

BENJAMIN, W. El narrador. Trad. Pablo Oyarzún Robles. Santiago de Chile: Ediciones Metales Pesados, 2008.

BENJAMIN, W. "Doctrina de lo semejante" y "Sobre la facultad mimética". In: Obras II, v. 1. Trad. Jorge Navarro Pérez. Madrid: Abada Editores, 2007.

BENJAMIN, W. "Experiencia y pobreza". In: Discursos interrumpidos I. Trad. Jesús Aguirre. Madrid: Editorial Taurus, 1973.

BENJAMIN, W. "Sobre algunos temas en Baudelaire". In: Iluminaciones II. Baudelaire. Un poeta en el esplendor del capitalismo. Trad. Jesús Aguirre. Madrid: Taurus Ediciones, 1972.

BOHNHOFF, L. "Roland Barthes: el ensayo y la ética de la evasión". Badebec, Rosario, v. 9, n. 17, pp. 143-163, 2019.

BORGES, J. L. "La muralla y los libros". In: Otras inquisiciones. Buenos Aires: Sudamericana, 2016.

BORGES, J. L. "Pensamiento y poesía". In: Arte poética. Seis conferencias. Barcelona: Editorial Crítica, 2001.

BUCK-MORSS, S. Walter Benjamin, escritor revolucionario. Trad. Mariano López Seoane. Buenos Aires: Interzona Editora, 2005.

CONTRERAS, S. En torno al realismo y otros ensayos. Rosario: Nube Negra Ediciones, 2018.

CRISORIO, B.; SÁNCHEZ, S. "Las piedras sobre el borde del círculo. Disquisiciones sobre La cámara lúcida de Roland Barthes y sus posibles vínculos con Fotos tuyas de Inés Ulanovsky". Estudios de Teoría Literaria. Revista digital: artes, letras y humanidades, Mar del Plata, v. 9, n. 19, pp. 155-167, 2020.

DELEUZE, G. "Sobre la diferencia entre la ética y una moral". In: Spinoza: Filosofía práctica. Trad. Antonio Escohotado. Buenos Aires: Tusquets Editores, 2006 [1981].

DOMÈNECH, J. M. C. "Modos de ver, formas de pensar: una genealogía de la posvisión". Novos Olhares - Revista de Estudos sobre Práticas de Recepção a Produtos Midiáticos, São Paulo, v. 9, n. 1, pp. 50-70, 2020.

GIORDANO, A. Con Barthes. Santiago de Chile: Marginalia Editores, 2016.

KRISTEVA, J. "La palabra, el diálogo y la novela". In: Semiótica 1. Trad. José Martín Arancibia. Madrid: Editorial Espiral, 1978.

MONTAIGNE, M. E. de. "Del arrepentimiento". In: Ensayos. Trad. Graciela Isnardi. Buenos Aires: Losada, 2011.

SAMOYAULT, T. "Barthes y la fotografía". Revista Aportes de la Comunicación, Santa Cruz de la Sierra, trad. Jhonny Gutierrez Moreno y Natalia Baudion, n. 19, pp. 62-69, 2015.

VEDDA, M. "Anatomía de la melancolía: Acedia y alienación en Walter Benjamin y Siegfried Kracauer". La biblioteca, Buenos Aires, n. 14, pp. 204-220, 2014.

VIVEROS CELÍN, C. E. "Fotografía, autobiografía y autoetnografía en Mitos: El Cuadrado del Tiempo". Revista KEPES, Caldas (Colombia), A 17, n. 22, pp. 465-500, 2020.

Recebido em: 14/04/2021 Aceito em: 27/06/2021

Referência eletrônica: BOHNHOFF, Leandro. El camino del medio: Barthes entre Benjamin y Adorno. Criação \& Crítica, n. 30, p., set. 2021. Disponível em: $<$ http://revistas.usp.br/criacaoecritica>. Acesso em: dd mmm. aaaa. 